\title{
Development of High Yielding Glutinous Cytoplasmic Male Sterile Rice (Oryza sativa L.) Lines through CRISPR/Cas9 Based Mutagenesis of $W x$ and TGW6 and Proteomic Analysis of Anther
}

\author{
Yue Han ${ }^{1,+}{ }^{+}$Dengjie Luo ${ }^{1, \dagger}{ }^{+}$Babar Usman ${ }^{1}$, Gul Nawaz ${ }^{1}$, Neng Zhao ${ }^{1}$, Fang Liu ${ }^{1}$ and \\ Rongbai Li ${ }^{1,2, *}$ \\ 1 College of Agriculture, State Key Laboratory for Conservation and Utilization of Subtropical \\ Agro-Bioresources, Guangxi University, Nanning 530004, China; 17739899868@163.com (Y.H.); \\ luodengjie01@126.com (D.L.); babarusman119@gmail.com (B.U.); gulnawazmalik@yahoo.com (G.N.); \\ nengzhao_gxu@163.com (N.Z.); liufang1975@163.com (F.L.) \\ 2 Guangxi Academy of Agricultural Sciences, Guangxi, Nanning 530007, China \\ * Correspondence: lirongbai@126.com; Tel.: +86-136-0009-4135 \\ + These authors contributed equally to this work.
}

Received: 8 November 2018; Accepted: 30 November 2018; Published: 3 December 2018

check for updates

\begin{abstract}
Development of high yielding and more palatable glutinous rice is an important goal in breeding and long-standing cultural interaction in Asia. In this study, the TGW6 and Wx, major genes conferring 1000 grain weight (GW) and amylose content (AC), were edited in a maintainer line by CRISPR/Cas9 technology. Four targets were assembled in pYLCRISPR/Cas9Pubi-H vector and $\mathrm{T}_{0}$ mutant plants were obtained through Agrobacterium mediated transformation with $90 \%$ mutation frequency having $28 \%$ homozygous mutations without off-target effects in three most likely sites of each target and expression level of target genes in mutant lines was significantly decreased $(P<0.01)$, the GW and gel consistency $(\mathrm{GC})$ were increased, and the AC and gelatinization temperature (GT) were decreased significantly and grain appearance was opaque, while there was no change in starch content (SC) and other agronomic traits. Mutations were inheritable and some $\mathrm{T}_{1}$ plants were re-edited but $\mathrm{T}_{2}$ generation was completely stable. The pollen fertility status was randomly distributed, and the mutant maintainer lines were hybridized with Cytoplasmic Male Sterile (CMS) line 209A and after subsequent backcrossing the two glutinous CMS lines were obtained in $\mathrm{BC}_{2} \mathrm{~F}_{1}$. The identified proteins from anthers of $\mathrm{CMS}$ and maintainer line were closely associated with transcription, metabolism, signal transduction, and protein biosynthesis. Putative mitochondrial $\mathrm{NAD}^{+}$-dependent malic enzyme was absent in CMS line which caused the pollen sterility because of insufficient energy, while upregulation of putative acetyl-CoA synthetase and Isoamylase in both lines might have strong relationship with CMS and amylose content. High yielding glutinous CMS lines will facilitate hybrid rice breeding and investigations of proteins linked to male sterility will provide the insights to complicated metabolic network in anther development.
\end{abstract}

Keywords: rice; CRISPR/Cas9; Wx; TGW6; mutations; maintainer; cytoplasmic male sterile; amylose content; anther; protein

\section{Introduction}

The rice (Oryza sativa L.) is an important widely adapted food crop and $20 \%$ of the world's dietary energy supply which is feeding more than half of the world's population and 3 billion people uptake rice daily [1,2]. Due to the fast-growing population, the global rice consumption is projected to increase 
from 450 million tons in 2011 to about 490 million tons in 2020 and $40 \%$ more rice is needed to be produced by 2050 to meet people's demand for food [3,4]. The cytoplasmic male sterility (CMS) is the foundation to exploit the heterosis of hybrid rice which uses a three-line system consisting of a cytoplasmic male sterile (CMS) line (A line), a maintainer (B), and a restorer (R line) for hybrid seed production [5]. China is the pioneer of hybrid rice production and with the development of latest breeding tools the yield of rice has been increased more than $20 \%$ and newly developed genotypes performing better than conventional verities and now accounts more than half of the annual rice planting area in China [6]. The development of new CMS has become the main interest of breeders because very few genotypes exhibit a strong restoration ability as effective restorer for CMS in the development of hybrid rice $[7,8]$. Yield and quality are typical quantitative traits governed by multiple genomic loci, while yield is directly depends on grain weight (GW) which is mainly determined by the synthesis and accumulation of starch in the endosperm of the grain $[9,10]$. To solve this problem, we must resort to new technologies and new genetic improvement strategies. Starch is one of the important indicators for evaluating rice quality and $90 \%$ of rice endosperm is starch [11].

Rice waxy gene $W x$-encoded granular bound starch synthase I (GBSSI), also known as Waxy protein is the major gene controlling amylose synthesis in endosperm [12]. Wx gene differentiates into alleles $W x^{a}$ and $W x^{b}$, indica rice is dominated by $W x^{a}$ which confers higher amylose content by producing 10-fold higher mRNA and protein level than $W x^{b}$ while japonica rice is dominated by $W x^{b}$ with lower amylose content $[13,14]$. Wx exon or intron structural change would affect $W x$ expression by affecting messenger RNA (mRNA) stability [12,15]. Several studies have reported that mutations in the functional site of the $W x$ gene led to 14.6 to $2.6 \%$ reduced amylose content $(\mathrm{AC})$ in rice transgenic lines and hybrids obtained with mutant lines [15-23], while $W x$ overexpression lines showed increased AC by 6-11\% [24].

At present, the GW related genes that have been cloned including qSW5/GW5 [25,26], TGW6 [27], GS3 [28], GS5 [29], GW2 [30], GW8/OsSPL16 [31], qGL3/qGL3-1/GL3.1 [32-34], GW7 [35], and OsSPL13 [36]. Among them, TGW6 is one of the most important genes regulating rice GW traits, which encodes a purine acetic acid-glucose hydrolase. Its loss-of-function mutation causes a decrease in the content of indoleacetic acid in the endosperm resulted in increased cell numbers which finally resulted with increased grain length and GW with 15\% enhanced production of rice [27]. Rice genes including DEP1, GS3, GW2, GS5, Gn1a, and TGW6, that are negative regulators of grain size and number and grain weight has been knocked-out to improve yield [37,38], and CRISPR/Cas9 based simultaneous mutations of GW2, GW5, and TGW6 resulted in 29.3\% increase in GW [39]. This suggests that generation of mutation in major yield related genes in a single cultivar would be helpful to increase large scale production of rice.

With the development of some new molecular biology techniques such as CRISPR/Cas9 (clustered regulatory interspersed short palindromic repeat/CRISPR associated proteins) a lot of achievements has been made in plants and animals. CRISPR/Cas9 technology is widely used to study the gene function and regarded as the third-generation genome-editing tool established after zinc finger nucleases (ZFNs) and transcription activator-like effector nucleases (TALEN), based on guided RNA (gRNA) engineered nucleases, which is most applicable due to their simplicity, efficiency, and versatility [40,41]. CRISPR/Cas9 make a double-stranded break (DSB) in the target DNA which is subsequently repaired by natural repair mechanism of homologous recombination (HR) precise pathway or non-homologous end joining (NHEJ) [42], which creates random insertions and deletions and results in targeted gene knockouts or gene replacement $[40,43,44]$. CRISPR/Cas9 is the most advanced genome editing tool in plant biology $[45,46]$ and has been widely used in animals, yeast, human non-human cell lines [42,47,48], as well as in the model species A. thaliana and N. benthamiana [43,49], as well as crops such as rice [50-52], wheat [53], maize [54], potato [55], and tomato [56].

Conventional plant breeding techniques are effective but laborious and time consuming, therefore we used CRISPR/Cas9-mediated gene editing to introduce a loss-of- function mutations into the $W x$ and TGW6 genes associated with lower AC and increase yield in rice maintainer line 209B. Our results show that mutations in the $W x$ and TGW6 gene produce decreased AC and enhanced yield in rice 
CMS line offering an effective strategy of accelerating the hybrid rice breeding program. Through one generation of hybridization and two generations of backcrossing with mutant maintainer lines as the male parent and 209A as female parent, the glutinous cytoplasmic male sterile lines (CMS) were successfully achieved. The protein of CMS line pollen and mutant maintainer line were separated by two-dimensional electrophoresis and sodium dodecyl sulphate-polyacrylamide gel electrophoresis (SDS-PAGE) and differentially expressed spots were analyzed. This study gave new insights into the mechanism of CMS and maintainer lines and demonstrated the power of proteomic in plant biology. Present study showed that the CRISPR/Cas9 technology provides the tool set to fasten the rice breeding program to achieve desired agronomic characters and improved yield.

\section{Materials and Methods}

\subsection{Rice Material, CRISPR/Cas9, and gRNA Vectors}

The cytoplasmic male sterile line 209A and its maintainer line 209B developed by Professor Li Rongbai, were collected from Rice Research Institute of Guangxi University. The maintainer line 209B was used for genetic transformation to which have the characteristics of resistance to drought and blast with compact plant type. Plants were grown in the experimental field of Guangxi University during normal rice growing season and maintained regularly. The Cas9 vector pYLCRISPR/Cas9-MT(I) and the gRNA vectors (OsU6a, OsU6b, OsU6c, and OsU3m) (Figure 1) were provided by Professor Liu Yaoguang, South China Agricultural University, Guangzhou, China.


Figure 1. Maps of pYLCRISPR/Cas9-MT(I) and pYL-U3/U6a-b-gRNA vectors. (a) The binary vector with Cas $9 p$ driven by maize ubiquitin promoter $\left(\mathrm{P}_{\mathrm{Ubi}}\right)$. The key sequences and restriction sites for Golden Gate ligation are shown. The expression of the sgRNA scaffold is driven by the rice U6a/U3 small nuclear RNA promoters; the expression of hygromycin (HPT) is driven by 2 CaMV35S promoters. NLS: nuclear localization signal; Tnos: gene terminator; LB and RB: left border and right border, respectively. (b) The physical map of the sgRNA intermediate plasmids. U3/U6 promoters from rice used for preparation of multiple sgRNA expression cassettes in single binary constructs. (c) BsaI sites $(1,2)$ in the sgRNA plasmids and their sequence information. These BsaI-cutting (small arrows) sites of the plasmids makes compatible sites for ligation by generating distinct non-palindromic ends to the U3/U6 promoters and a common end to the sgRNA sequence. Modified from Ma et al. (2015a) [57]. 


\section{2. $g R N A$ Target Selection and Synthesis of Oligonucleotide Strands}

The gRNA target sequences were designed according to the exon sequence of $W x$ (LOC_Os06g04200) and TGW6 (LOC_Os06g41850) provided by the Rice Genomics Annotation website (http://rice.plantbiology.msu.edu/) (Figure 2). The targets were $20 \mathrm{bp}$ long gRNA sequences followed by the protospacer adjacent motif (PAM) NGG. The targets were selected with high GC\%, low off-target score (Table S1) in exon regions by using online toolkit CRISPR-GE (http: //skl.scau.edu.cn/) and sgRNA structures (Figure S1) were developed by online tool CRISPR-P 2.0 (http:/ / crispr.hzau.edu.cn/CRISPR2/). The CRISPR/Cas9 constructs that we designed to target Wx were in the first exon (WxT1: bases 1522-1541; WxT2: bases 2011-2030), with expected targeted mutations. The both targets for TGW6 were also designed in the exon region (TGW6T1: bases 184-203; TGW6T2: bases 751-770) and expected mutations were in the coding region (Figure 2). The gRNA sequences were aligned and validated by using National Center for Biotechnology Information (NCBI) (https:/ / blast.ncbi.nlm.nih.gov/Blast.cgi) and non-specific targets were excluded. Oligonucleotide sequences were synthesized by Beijing Genomics Institute (BGI) and shown in Table S2.

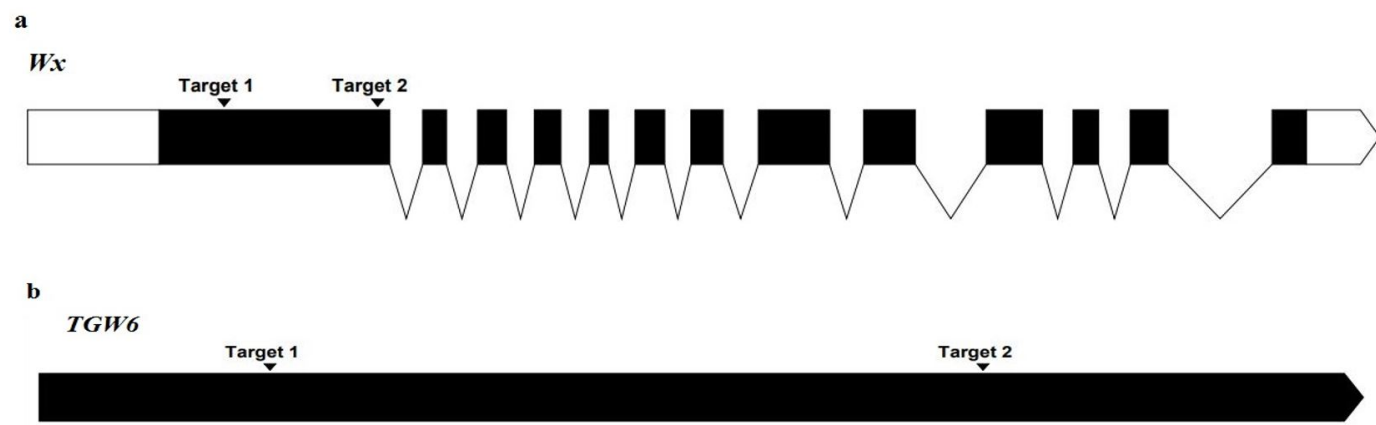

Figure 2. Schematic diagram of gene structures and target sites of the gRNA in the genes locus. (a) Position of two targets in Wx gene and (b) both targets in TGW6 gene locus.

\subsection{Vector Construction}

The selected binary plasmids were isolated from E. coli (Escherichia coli) TOP10F' strains according to the previous established methods [57,58] with some modifications (Figure S2). The target site containing sequence primers WxgRT1/OsU6aWxT1 and WxgRT2/OsU6bWxT2 TGgRT1/OsU6cTGT1 and TGgRT2/OsU3TGT2, (Table S2) were combined by annealing, and then the target site sequence-containing chimeric primers were cloned into the sgRNA expression cassettes pYLsgRNA-U6a, pYLsgRNA-U6b, pYLsgRNAU6c and pYLsgRNA-U3m at a BsaI site (Figure S3). The integrated sgRNA expression cassettes were then amplified by nested polymerase chain reaction (PCR) using U-F/Reverse adapter primers and $g R-R$ for the first round, and the corresponding site-specific primers Pps-R/Pgs-2, Pps-2/Pgs-3, Pps-3/Pgs-4, and Pps-4/Pgs-L (Table S2) for the overlapping PCR (Figure S4) to ligate four-target-sgRNAs expression cassettes into the pYLCRISPR/Cas9Pubi-H vector and ligation product was transformed into DH5 $\alpha$ competent cells according to the established protocol [20] with some modifications (Figure S5). The monoclonal inoculation culture was picked and were amplified by using SPL1 and SP-R primers (Table S2) and the clones confirming the product length ware sent to Beijing Genomics Institute (BGI) for sequencing. 


\subsection{Agrobacterium-Mediated Transformation of Rice Callus}

The constructed plasmid was transformed into Agrobacterium EHA105 by electroporation according to the established method [59], and positive clones were used for rice callus transformation and transformed plants were obtained by hygromycin screening.

\section{5. $T_{0}$ Genotypinng}

The genomic DNA of $\mathrm{T}_{0}$ mutant lines was extracted by cetyl trimethylammonium bromide (CTAB) method and PCR amplification was performed by using target specific primers for $W x$ gene Target1 OsWaxyT1F/OsWaxyT1R, and for Target2 OsWaxyT2F/OsWaxyT2R, and for TGW6 Target1 Tgw6-T1F/Tgw6-T1R, for Target2 Tgw6-T2F/Tgw6-T2R (Table S2). The amplified products were visualized by $1 \%$ agarose gel electrophoresis and then sent to BGI for sequencing and mutations were decoded by using online tool DSDecodeM (http://skl.scau.edu.cn/dsdecode/). The multiple amino-acid sequence alignment was performed by using Clustal Omega online tool (https:/ /www. ebi.ac.uk/Tools/msa/clustalo/). The off-target regions were selected from CRISPR-GE online tool (http://skl.scau.edu.cn/offtarget/).

\subsection{Identification of T-DNA Free Mutant Lines and Cross Section Analysis of Grain Endosperm}

The genomic DNA of $\mathrm{T}_{1}$ and $\mathrm{T}_{2}$ generations was extracted and amplified by using Cas9-F and Cas9-R specific primers (Table S2). The amplified product was subjected to $1 \%$ agarose gel to check the T-DNA free mutant plants. Scanning electron microscopy was used to observe the cross section of the mutant and its wild type (WT) mature grain according to the previous established method [60].

\subsection{Expression Analysis}

Total RNA was extracted from WT and $\mathrm{T}_{1}$ mutant plants by using TaKaRa MiniBEST Plant RNA Extraction Kit according to manufacturer instructions. The specific primers for $W x$ gene $W-F / W-R$ and TG-F/TG-R were used for TGW6 (Table S2). The rice OsActin gene was used as internal control and $20 \mu \mathrm{L}$ reaction was prepared with $2 \mu \mathrm{L}$ cDNA, $0.4 \mu \mathrm{L}$ each of the forward and reverse primers, $10 \mu \mathrm{L}$,

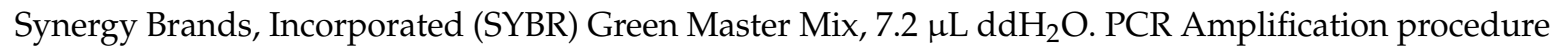
was as followed, 30 s at $94{ }^{\circ} \mathrm{C}, 5 \mathrm{~s}$ at $94{ }^{\circ} \mathrm{C}$, and $30 \mathrm{~s}$ at $60^{\circ} \mathrm{C}$ with 45 cycles. The relative expression of genes was calculated from three biological replicates per sample according to the $2^{-\Delta \Delta \mathrm{Ct}}$ method [61].

\subsection{Determination of $A C, S C, G C$, and $G T$}

The $A C$ of $T_{0}, T_{1}$, and $T_{2}$ generations were measured after 3 months of harvesting. The total AC and SC were measured by using Megazyme Amylose Assay Kit (KAMYL), Guangzhou, China and Total Starch Assay Kit (AA/AMG), Guangzhou, China. The GC was evaluated for random five samples [62] and alkali digestion test was used to estimate GT [63].

\subsection{Phenotyping}

The data was recorded in five plants per line for $\mathrm{GW}(\mathrm{g})$ in $\mathrm{T}_{0}, \mathrm{~T}_{1}$, and $\mathrm{T}_{2}$ generation while the data for main agronomic traits was recorded in $\mathrm{T}_{2}$ generation, such as plant height $(\mathrm{PH})(\mathrm{cm})$, number of panicles (NOP), flag leaf length (FLL) $(\mathrm{cm})$, flag leaf width $(\mathrm{FLW})(\mathrm{cm})$, panicle length $(\mathrm{PL})(\mathrm{cm})$, grains per spike (GPS), and seed setting rate (SSR) (\%), as described previously [28]. 


\subsection{Backcrossing and Observation of Pollen and Spikelet Fertility}

The mutant maintainer lines T2-4-2, T2-7-1, T2-14-4, T2-19-3, T2-23-5, and 209A sterile line were crossed with two CMS lines MX-G1 and MX-G2 and during next season the 12 testcrosses along with respective male parents were transplanted and fertility test was performed at flowering stage. The pollen and spikelet fertility test were done by $1 \%(m / v) \mathrm{I}_{2}-\mathrm{KI}$ solution at flowering stage to evaluate the fertility restoration ability of restorer lines. The young spikelets were collected in the early morning to determine pollen fertility and kept in the jar about $2 \mathrm{~h}$ for opening the spikelets. The pollen was stained with KI solution and observed under a compound microscope. The stained pollens with round shape and well developed were considered as viable and irregular shaped and non-stained pollens were counted as sterile pollens. The criteria for classifying the parental lines as maintainers and restorers were followed as proposed previously [64]. Subsequent backcrosses were made between mutant lines as male and 209A as female to develop glutinous CMS lines.

\subsection{Pollen Protein Analysis}

Anthers of CMS line and maintainer line were taken from upper part of one panicle inside in the spikelet and located in the middle of panicles were collected and protein was extracted according to previous established method [65]. The protein separation was performed through SDS-PAGE gel electrophoresis [66] and proteins were identified by peptide mass fingerprinting (PMF) [67]. The analysis was performed with mass to charge ratio $(\mathrm{m} / \mathrm{z})$ formula to identify the monoisotopic masses and search in the NCBInr database using MASCOT (Matrix Science) software.

\subsection{Statistical Analysis}

The data were analyzed using SPSS 16.0 Statistical Software Program. The graphs were developed by GraphPad Prism (version 7.0, GraphPad Software Inc., San Diego, CA, USA).

\section{Results}

\section{1. gRNA Design and Vector Construction}

The 20bp long target sites were chosen in $W x$ and TGW6 codon region and predictive cleavage site for the TGW6 was 5pb upstream from initiation codon (ATG) and 72bp downstream of $W x$. The sgRNA expression cassette was generated by overlapping PCR (Figure 3a) and ligating of the target adaptors to the BsaI-digested sgRNA intermediate plasmid and amplified products were successfully assembled in to pYLCRISPR/Cas9-MT(I) binary plasmid with Golden Gate ligation method (Ma et al. 2015). The ligation product was transformed to E. coli and positive clones were verified. The CRISPR/Cas 9 binary plasmid was constructed and sequencing peaks confirmed that four targets were assembled in the plasmid successfully (Figure 3d,e). 

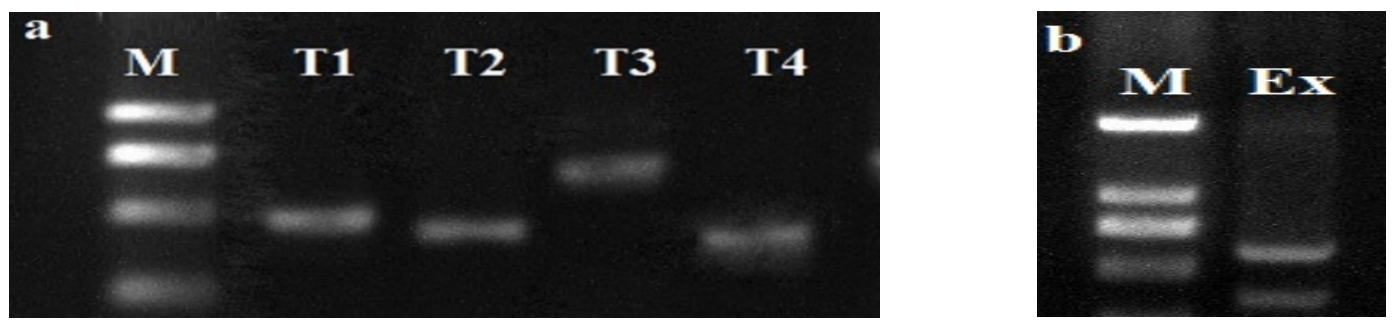

c
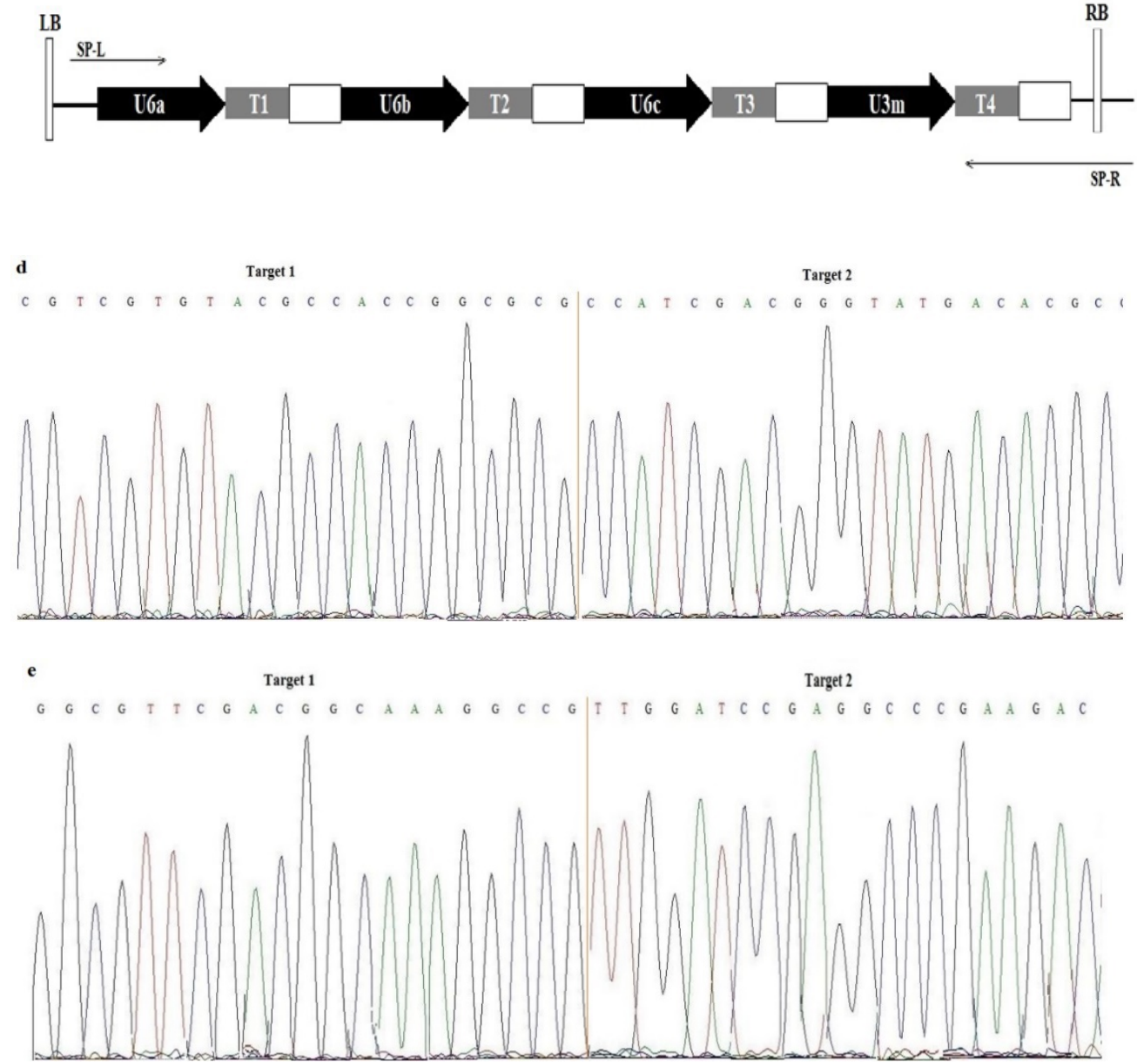

Figure 3. (a) sgRNA expression cassette after second round of PCR, M:2000, T1 (OsU6a-gRNA): 629 bp, T2 (OsU6b-sgRNA): 564 bp, T3 (OsU6c-sgRNA): 767 bp, and T4 (OsU3m-sgRNA): 515 bp, M: molecular marker. (b) sgRNA expression cassette after mixing and purification, Ex: expression cassette. (c) Illustration of the assembly of four sgRNA expression cassette into a pYLCRISPR/Cas9-MT(I) vector by single Golden Gate ligation. SP-L1 and SP-R are the flanking primers used to amplify the ligated sgRNA expression cassettes. (d) Sequencing results for the two target sequences of $W x$ gene and (e) and two targets of TGW6. 


\section{2. $T_{0}$ Genotyping and Off-Target Analysis}

Total 55 positive mutant plants were obtained, and the DNA of 25 plants was extracted by CTAB method to analyze the mutations in target sites. The sequencing results showed that for Target 1 of $W x$ gene there were 10 homozygous mutant plants, 5 heterozygous, 7 bi-allelic, and 1 chimeric and 2 were WT; while, for the Target 2 of $W x$ gene, there were 4 homozygous mutant plants, 6 heterozygous, 10 bi-allelic and, 1 chimeric and 4 were WT. The mutation frequency for Target 1 of TGW6 gene was as; 9 homozygous, 7 heterozygous, 6 bi-allelic, 1 chimeric, and 2 WT and for Target 2 of TGW6 there were 5 homozygous, 8 heterozygous, 9 bi-allelic, 1 chimeric and 2 WT (Table 1). Five plants with good phenotype $(4,7,14,19,23)$ were selected and identified with deletions of DNA fragments between distinct target sites (Figure 4a,b). In two of these homozygous mutant plants (4 and 7) were found with large fragment deletion at target sites of both genes. The mutant plant (14) with bi-alleic mutations in both genes was also found. The DSBs occurred either specifically in the upstream of the PAM (Figure 4), or at imprecise sites thus eliminating the genomic sequence beyond the PAMs. However, we analyzed the limited number of amplicons per transformant so maybe the actual number of mutations might be higher. In 25 of the plants the WT sequences of both genes were also detected, suggesting that Cas 9 was inactive in these events. The average mutation types for both genes were $32 \%$ bi-allelic, $28 \%$ homozygous, $26 \%$ heterozygous, $4 \%$ chimeric, and $10.0 \%$ were WT (Table 1 ). The mutation rate for both genes was $90 \%$ and based on allele mutation types, for $W x$ gene $80 \%(4 / 5)$ of the mutations were simultaneous nucleotide deletions and insertions, $20 \%(1 / 5)$ of the mutations were only deletions with no insertions, and there were no mutations with only insertions (Figure 4a). The allelic mutation types for TGW6 were $60 \%$ deletions, $40.0 \%$ simultaneous deletions and insertions and there was no mutation with only insertions (Figure $4 \mathrm{~b}$ ). As for the deletion mutations, the $40 \%$ mutations were large fragment deletions ranging from -11 to -120 , while $60 \%$ were short ( $\leq 10 \mathrm{bp}$ ) deletions ranging from -1 to -6 and as for the insertion mutations, $90 \%(9 / 10)$ were $1 \mathrm{bp}$ insertions and $10 \%(1 / 5)$ were +2 insertions (Figure 4). Comparison of WT and mutant's deduced amino acid sequences revealed that mutations resulted in changed conserved amino acid sequences (Figure 5).

The off-target predictions by CRISPR-P tool were analyzed and three off-target sites were selected for each target and examined by PCR based sanger sequencing in $\mathrm{T}_{0}$ generation. The results showed that there were no off-target effects in the selected putative loci and targeted mutation were easily detected (Table S3).

Table 1. Mutation rate of $\mathrm{T}_{0}$ generation

\begin{tabular}{|c|c|c|c|c|c|c|c|c|}
\hline \multirow[b]{2}{*}{ Gene } & \multirow{2}{*}{\multicolumn{2}{|c|}{ Target Site }} & \multicolumn{5}{|c|}{ Mutation Type } & \multirow[b]{2}{*}{ Total } \\
\hline & & & Bi-Allelic & Homozygous & Heterozygous & Chimeric & WT & \\
\hline \multirow{4}{*}{$W x$} & \multirow{2}{*}{ Target 1} & No. of plants & 7 & 10 & 5 & 1 & 2 & 25 \\
\hline & & Mutation rate $(\%)$ & 28 & 40 & 20 & 4 & 8 & 100 \\
\hline & \multirow{2}{*}{ Target 2} & No. of plants & 10 & 4 & 6 & 1 & 4 & 25 \\
\hline & & Mutation rate $(\%)$ & 40 & 16 & 24 & 4 & 16 & 100 \\
\hline \multirow{4}{*}{ TGW6 } & \multirow{2}{*}{ Target 1} & No. of plants & 6 & 9 & 7 & 1 & 2 & 25 \\
\hline & & Mutation rate (\%) & 24 & 36 & 28 & 4 & 8 & 100 \\
\hline & \multirow{2}{*}{ Target 2} & No. of plants & 9 & 5 & 8 & 1 & 2 & 25 \\
\hline & & Mutation rate $(\%)$ & 36 & 20 & 32 & 4 & 8 & 100 \\
\hline
\end{tabular}


a



b



Figure 4. Nucleotide sequences at the target site in the $5 \mathrm{~T}_{0}$ mutant rice plants. (a) Mutations induced at $W x$ and (b) TGW6 target sites. The recovered mutated alleles are shown below the wild-type (WT) sequence. The target sites nucleotides are shown in black capital letters and black dashes. The red capital letters indicate inserted nucleotides and the apostrophe followed to red capital letters indicates inserted nucleotides are not shown in. The Protospacer Adjacent Motif (PAM) site nucleotides are shown in yellow background letters. The red dashes indicate the deleted nucleotides. - and + indicate deletion and insertion of the indicated number of nucleotides, respectively - / + indicates simultaneous deletion and insertion of the indicated number of nucleotides; GW: grain weight.



b



Figure 5. Amino acid sequence alignment for WT and five transformants in $\mathrm{T}_{0}$ generation. (a) Amino acid sequences showing the alignment about $W x$ gene, and (b) TGW6 mutant plants and WT. The deleted amino acids are shown by black hyphens, the translation was terminated earlier in mutants 4 and 7. Highly conserved and partially conserved amino-acid sequences are indicated with asterisks $\left(^{*}\right)$ and dash (-) signs, respectively. 


\subsection{Expression Level of Target Genes in WT and Mutant Lines}

qPCR was used to detect the relative expression of TGW6 and $W x$ gene of $\mathrm{T}_{0}$ plants. The expression of WT was not altered, and the expression of mutant plants was substantially downregulated in the $W x$ and TGW6 mutants compared with WT $(P<0.01$, Figure 6) indicating that mutations have successfully affected the target genes expression. The homozygous mutant lines $(4,7)$ with large fragment deletions showed lower expression level of $W x$ and TGW6 gene.


Figure 6. Relative expression analysis of target genes (a) Wx and (b) TGW6 in wild type (WT) and mutant plants. Transcripts level was determined by Q-RT-PCR with cDNA generated from leaves of four-week-old plants. The expression values of the individual genes were normalized by using expression level of rice Actin gene as an internal standard. The data represents the mean values of three independent samples [Mean $\pm \mathrm{SD}$ (standard deviation)]. ${ }^{* *}$ indicates significant difference at $P<0.01$ ( $t$ test).

\subsection{Screening of T-DNA Free $T_{1}$ Generation and Seed Cross-Section Analysis}

We addressed the genetically modified (GM) related regulations and issue of social acceptance of GM foods and to avoid public controversy by removing the transgenes from CRISPR/Cas9- edited waxy rice lines by self-pollination in the $\mathrm{T}_{1}$ generation which allowed to produce non-GM lines containing the desired mutations. The DNA of $\mathrm{T}_{1}$ and $\mathrm{T}_{2}$ generations was extracted to investigate the possibility of obtaining rice lines harboring the desired modifications in target genes but without transferred DNA (T-DNA), the Cas9 gene specific primers Cas9-F and Cas9-R were used and amplified by PCR and T-DNA negative lines were selected for sequencing of the target regions. Notably, $13 \mathrm{~T}_{1}$ plants were failed to generate the Cas9-specific amplicon (Figure 7a). Similarly, the PCR assay also failed to detect the Cas 9 specific amplicon in the same 13 mutant lines of $T_{2}$ generation (Figure $7 \mathrm{~b}$ ). These results showed that T-DNA-free plants carrying the desired gene modifications can be acquired through genetic segregation in later generations.

Scanning electron microscopy of cross section of grain endosperm revealed that CRISPR/Cas9 mutant line showed opaque appearance compared to WT endosperm. The starch granules in the cross-section of WT grain were packed like polyhedral structure but in the mutant line a greater number of small and irregularly arranged starch granule structures were observed (Figure $7 \mathrm{~d}-\mathrm{g}$ ), indicating a change in the mature grain of mutant line. The change in structure may cause the scattering of the light as it passes and resulted in opaque appearance. 

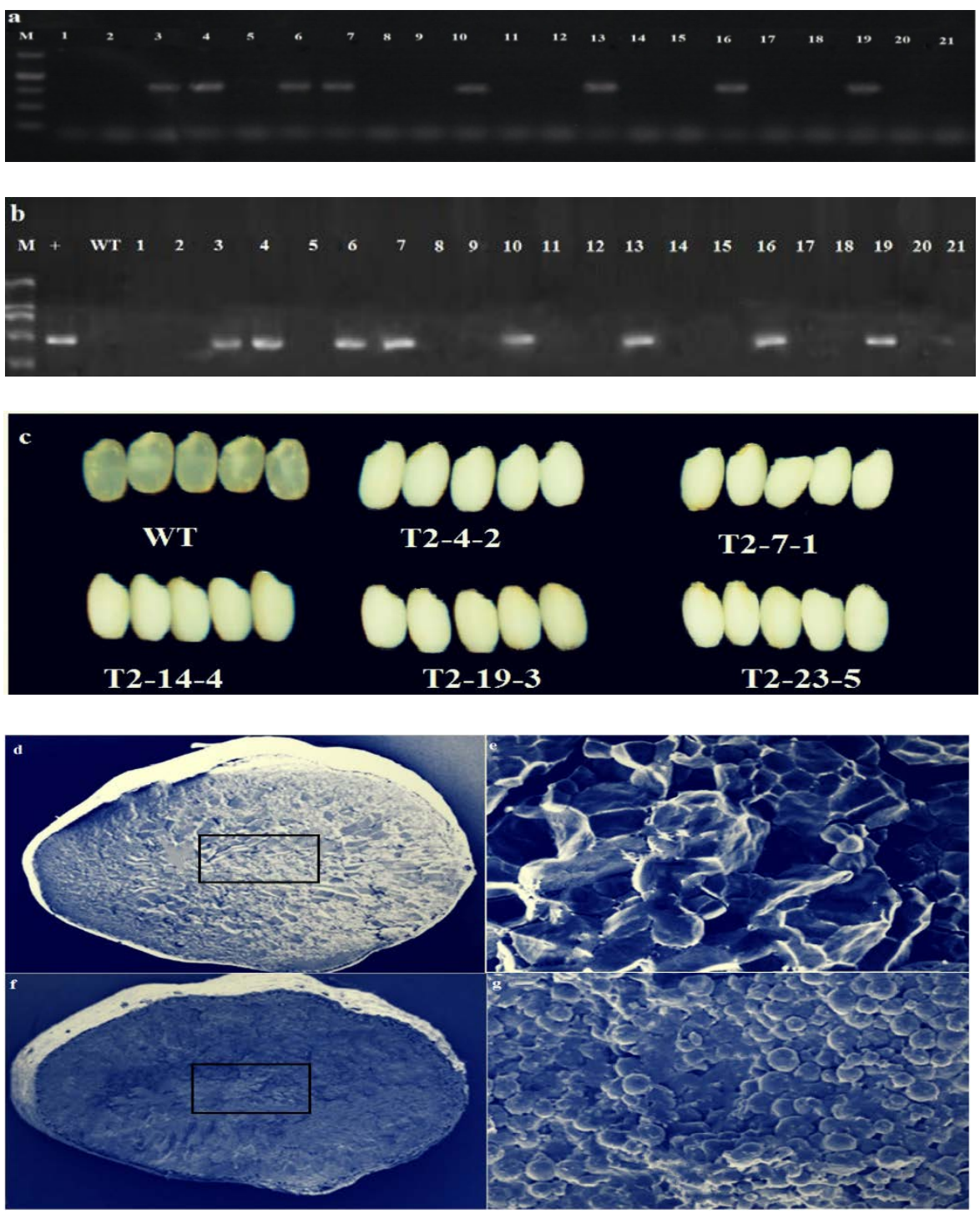

Figure 7. PCR-based identification of T-DNA-free rice mutant plants and seed analysis of WT and mutant line (T2-4-2). PCR products amplified from the progenies of (a) $T_{1}$ and (b) $T_{2}$ mutant lines genomic DNA using the Cas9 specific primers Cas9-F and Cas9-R. WT: wild-type, M: DNA molecular marker, +: positive control (c) Grain phenotype of WT and mutant lines. Cross-section analysis of endosperm in WT $(\mathbf{d}, \mathbf{e})$ and mutant line $(\mathbf{f}, \mathbf{g})$.

\subsection{Transmission of Mutations in $T_{1}$ and $T_{2}$ Generations}

The sequencing results showed that mutations in $\mathrm{T}_{0}$ generation were not stable in some mutant plants but $T_{2}$ generation was completely stable. The mutant plants of 7-1,14-4, and 19-3 lines in $T_{1}$ generation exhibited insertions and deletions in the $W x$ target regions, while 4-2 and 23-5 showed consistent mutations in $\mathrm{T}_{0}$ and $\mathrm{T}_{1}$ (Figure 8a; Figure 4a). The mutant plants of 4-2, 7-1, and 23-5 showed insertions and deletions at TGW6 target sites in $\mathrm{T}_{1}$ generation, while mutations in 23-5 and 14-4 were similar in $T_{0}$ and $T_{1}$ generation (Figure $8 b$; Figure $4 b$ ). The transmission of mutations from $T_{1}$ to $T_{2}$ generation were investigated and sequencing results of $T_{2}$ plants showed that the mutations were consistent with the $T_{1}$ generation without any insertions or deletions, indicating that the $T_{2}$ generation has been stabilized (Figure 8a,b; Figure 4a,b). 


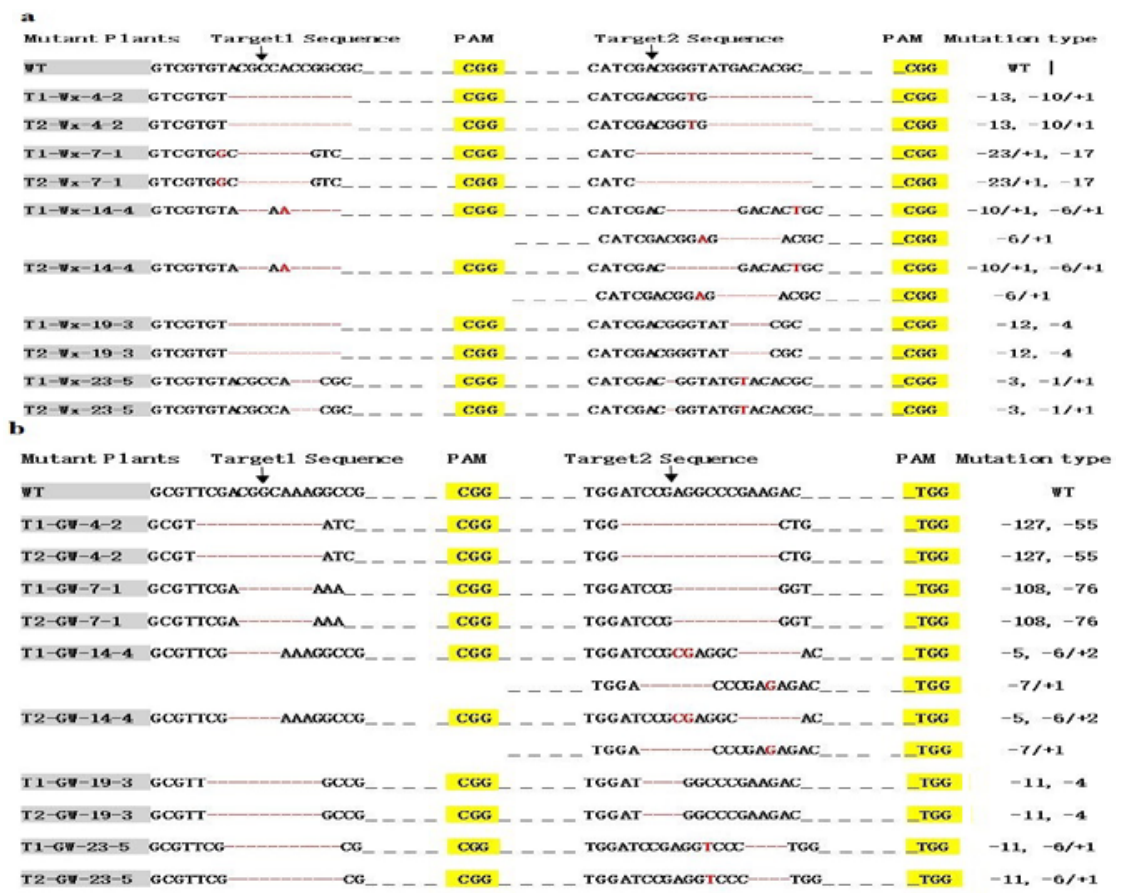

Figure 8. Sequence alignment for transmission of mutations at (a) $W x$ and (b) TGW6 target sites in $\mathrm{T}_{1}$ and subsequent $T_{2}$ generations. The targeted sequence is shown in capital black letters and the PAM sequence in yellow background. Insertion is represented by red letters, and deletion by red hyphens.

\section{6. $A C, G C, G T$, and $S C$}

AC of $T_{0}, T_{1}$, and $T_{2}$ generations were determined while the GC and GT was recorded for $\mathrm{T}_{2}$ generation. The AC of mutant lines were significantly decreased $(P<0.01)$ as $18.2 \%$ to $1.7 \%$. The homozygous mutant lines with long fragment deletion $(4,7)$ showed more decreased AC than heterozygous and bi-allelic mutants (Table 2). Grains of mutant plants were white and fully opaque in contrast with the typical non-waxy WT (Figure 7c). There was no effect on other grain quality traits, as result showed that total SC was unchanged in mutant and WT plants (Table 2). Another trait related to eating and cooking, GT, was also greatly decreased in the mutant plants and GC was increased as compared to the WT (Table 2).

Table 2. Amylose content, GC, and GT of WT and mutant plants.

\begin{tabular}{|c|c|c|c|c|c|c|c|c|}
\hline $\mathrm{T}_{0}$ plant & AC (\%) & $T_{1}$ plants & $\mathrm{AC}(\%)$ & $\mathrm{T}_{2}$ Plants & AC (\%) & $\mathrm{GC}(\mathrm{mm})$ & GT (ASV) & SC (\%) \\
\hline 4 & $2.6 \pm$ & $4-2$ & $1.7 \pm 0.1^{* *}$ & T2-4-2 & $1.8 \pm 0.1$ & $138.62 \pm 2.8$ & $3.12 \pm 0.9^{* *}$ & $62.5 \pm$ \\
\hline 7 & $3.6 \pm 0.3^{* *}$ & $7-1$ & $2.2 \pm 0.5^{* *}$ & $\mathrm{~T} 2-7-1$ & $2.1 \pm 0.3^{* *}$ & $129.65 \pm 3.9^{* *}$ & $3.09 \pm 1.1^{* *}$ & $63.2 \pm 2.3^{\mathrm{ns}}$ \\
\hline 14 & $10.5 \pm 0.2^{* *}$ & $14-4$ & $2.4 \pm 0.1^{* *}$ & T2-14-4 & $2.6 \pm 0.2^{* *}$ & $125.32 \pm 4.6^{* *}$ & $3.21 \pm 0.2 * *$ & $63.2 \pm 1.9^{\mathrm{ns}}$ \\
\hline 19 & $12.2 \pm 0.1^{* *}$ & $19-3$ & $2.8 \pm 0.3^{* *}$ & T2-19-3 & $2.7 \pm 0.2 * *$ & $114.22 \pm 2.6^{* *}$ & $3.19 \pm 0.8^{* *}$ & $62.8 \pm 2.9^{n s}$ \\
\hline 23 & $9.5 \pm 0.6^{* *}$ & $23-5$ & $3.2 \pm 0.5^{* *}$ & T2-23-5 & $3.1 \pm 0.1 * *$ & $111.56 \pm 5.2 * *$ & $3.24 \pm 0.6^{* *}$ & $64.5 \pm 3.4^{\mathrm{ns}}$ \\
\hline WT & $18.2 \pm 1.2$ & WT & $17.6 \pm 1.3$ & WT & $18.1 \pm 2.1$ & $58.65 \pm 3.7$ & $5.67 \pm 1.4$ & $62.97 \pm 2.7$ \\
\hline
\end{tabular}

Note: Data is shown the average of three independent samples, ${ }^{* *}$ indicate significant difference; ${ }^{\text {ns }}$ indicate non-significant difference, $\mathrm{mm}$, millimeters; ASV: alkali spreading value. Data listed in table are presented as means \pm SD, $(P<0.01)$. AC: amylose content; GC: gel consistency; GT: gelatinization temperature; SC: starch content.

\subsection{Yield and Yield Contributing Traits}

The results of the GW in $T_{0}, T_{1}$, and $T_{2}$ generation was recorded (Table 3), and results showed that the mutant plants significantly increased the GW (>5\%). As expected, the GW of mutant line (T2-4-2) was $24.0 \mathrm{~g}$ maximum, whereas T2-7-1 presented a GW of $23.1 \mathrm{~g}$ (Table 3). The GW of T2-14-4, T2-19-3, and T2-23-5 was 23.4 g, $23.1 \mathrm{~g}$ and $23.7 \mathrm{~g}$ respectively, which was greater than the value of $21.1 \mathrm{~g}$ recorded in WT (Table 3). However, there were no significant differences detected in the other 
main agronomic traits between mutant lines and WT, including the PH, NOP, FLL, FLW, PL, GPS, and SSR (Table 4).

Table 3. 1000 grain weight $(\mathrm{g})$ of mutant lines and $\mathrm{WT}$ in $\mathrm{T}_{0}, \mathrm{~T}_{1}$, and $\mathrm{T}_{2}$ generations.

\begin{tabular}{cccccc}
\hline T plants & GW $(\mathbf{g})$ & T $_{\mathbf{1}}$ Plants & GW (g) & T $_{\mathbf{2}}$ Plants & GW (g) \\
\hline 4 & $23.6 \pm 0.50^{*}$ & $4-2$ & $23.9 \pm 0.50^{*}$ & $\mathrm{~T} 2-4-2$ & $24.0 \pm 0.50^{*}$ \\
7 & $23.1 \pm 0.57^{*}$ & $7-1$ & $23.8 \pm 0.57^{*}$ & $\mathrm{~T} 2-7-1$ & $23.1 \pm 0.57^{*}$ \\
14 & $23.4 \pm 0.50^{*}$ & $14-4$ & $23.7 \pm 0.50^{*}$ & $\mathrm{~T} 2-14-4$ & $23.4 \pm 0.50^{*}$ \\
19 & $23.1 \pm 0.47^{*}$ & $19-3$ & $23.3 \pm 0.47^{*}$ & $\mathrm{~T} 2-19-3$ & $23.1 \pm 0.47^{*}$ \\
23 & $23.7 \pm 0.38^{*}$ & $23-5$ & $23.7 \pm 0.38^{*}$ & $\mathrm{~T} 2-23-5$ & $23.7 \pm 0.38^{*}$ \\
WT & $21.0 \pm 0.35$ & WT & $21.3 \pm 0.35$ & $\mathrm{WT}$ & $21.1 \pm 0.35$ \\
\hline
\end{tabular}

The data listed in the table are mean \pm standard error. ${ }^{*}$ indicate significant difference $(P<0.01)$. GW: grain weight.

Table 4. Main agronomic characters in $\mathrm{T}_{2}$ generation.

\begin{tabular}{|c|c|c|c|c|c|c|c|}
\hline $\mathrm{T}_{2}$ Plants & PH (cm) & NOP & FLL (cm) & FLW (cm) & PL (cm) & GPS & SSR (\%) \\
\hline T2-4-2 & $84 \pm 3.4^{\mathrm{ns}}$ & $9.5 \pm 5.4^{\mathrm{ns}}$ & $42.3 \pm 4.3^{\mathrm{ns}}$ & $1.7 \pm 0.2^{\mathrm{ns}}$ & $25.1 \pm 1.2^{\mathrm{ns}}$ & $191 \pm 6.7^{\mathrm{ns}}$ & $87.8 \pm 2.3^{\mathrm{ns}}$ \\
\hline $\mathrm{T} 2-7-1$ & $83 \pm 4.5^{\mathrm{ns}}$ & $8.8 \pm 2.6^{\mathrm{ns}}$ & $39.5 \pm 5.2^{\mathrm{ns}}$ & $1.6 \pm 0.1^{\mathrm{ns}}$ & $24.6 \pm 2.3^{\mathrm{ns}}$ & $195 \pm 6.9^{\text {ns }}$ & $87.9 \pm 4.5^{\mathrm{ns}}$ \\
\hline T2-14-4 & $85 \pm 2.7^{\mathrm{ns}}$ & $9.5 \pm 1.6^{\mathrm{ns}}$ & $43.2 \pm 2.1^{\mathrm{ns}}$ & $1.5 \pm 0.3^{\mathrm{ns}}$ & $23.9 \pm 1.5^{\mathrm{ns}}$ & $196 \pm 4.5^{\mathrm{ns}}$ & $88.9 \pm 6.2^{\mathrm{ns}}$ \\
\hline T2-19-3 & $86 \pm 3.6^{\mathrm{ns}}$ & $9.3 \pm 3.4^{\mathrm{ns}}$ & $44.6 \pm 1.9^{\mathrm{ns}}$ & $1.8 \pm 0.4^{\mathrm{ns}}$ & $25.1 \pm 2.4^{\mathrm{ns}}$ & $188 \pm 7.6^{\mathrm{ns}}$ & $88.4 \pm 1.3^{\mathrm{ns}}$ \\
\hline $\mathrm{T} 2-23-5$ & $85 \pm 2.8^{\mathrm{ns}}$ & $9.2 \pm 4.6^{\mathrm{ns}}$ & $43.3 \pm 2.5^{\mathrm{ns}}$ & $1.6 \pm 0.5^{\mathrm{ns}}$ & $23.9 \pm 3.1^{\mathrm{ns}}$ & $193 \pm 5.8^{\mathrm{ns}}$ & $86.9 \pm 2.8^{\mathrm{ns}}$ \\
\hline WT & $83 \pm 4.6$ & $9.5 \pm 2.9$ & $44.5 \pm 3.6$ & $1.7 \pm 0.2$ & $25.4 \pm 1.9$ & $192 \pm 4.9$ & $87.6 \pm 4.6$ \\
\hline
\end{tabular}

PH: plant height; NOP: number of panicles; FLL: flag leaf length; FLW: flag leaf width; PL: panicle length; GPS: grains per spike; SSR: seed setting rate; The data listed in the table are mean \pm standard error. ${ }^{n s}$ indicate non-significant difference.

\subsection{Pollen Fertility Status}

In the $\mathrm{T}_{3}$ generation, a total 16 lines $(4-2 \mathrm{~A}, 4-1 \mathrm{~A}, 4-4 \mathrm{~B}, 4-3 \mathrm{~A}, 4-5 \mathrm{C}, 4-7 \mathrm{~A}, 4-8 \mathrm{~A}, 7-5 \mathrm{~B}, 7-3 \mathrm{~A}, 14-4 \mathrm{~A}$, 14-4C, 19-3C, 19-5A, 19-3B, 23-5B, 23-7A) were assessed for pollen fertility status and pollen fertility rate was randomly distributed, which showed that CRISPR/Cas9 mutations did not affect the fertility status of maintainer lines. Among 16 mutant lines, the 3 genotypes (4-2A, 19-5A, 19-3B) were completely sterile (CS), 3 (4-8A, 7-5B, 7-3A) were sterile (S) and 2 (4-1A, 4-4B) were partially sterile (PS) which was considered as male sterile lines or A line. Six genotypes were found sterile (CS and S) having pollen fertility 0-9\% while two genotypes showed $10-29 \%$ pollen fertility. Two genotypes were recorded PS which is $12.5 \%$ of total (Table 5). Two genotypes were found partially fertile (PF) which is also $12.5 \%$ of total. Two genotypes were identified as fertile $(\mathrm{F})$ and four were fully fertile (FF) as these genotypes had above $70 \%$ and $80 \%$ pollen and spikelet fertility respectively, which is $37.50 \%$ of the total genotypes (Table S4).

Table 5. Classification of mutant lines based on pollen fertility status.

\begin{tabular}{cccc}
\hline S. No & Symbol & Fertility Status & Genotypes \\
\hline 1 & CS & Completely Sterile & $4-2 \mathrm{~A}, 19-5 \mathrm{~A}, 19-3 \mathrm{~B}$ \\
2 & S & Sterile & $4-8 \mathrm{~A}, 7-5 \mathrm{~B}, 7-3 \mathrm{~A}$ \\
3 & PS & Partially Sterile & $4-1 \mathrm{~A}, 4-4 \mathrm{~B}$ \\
4 & PF & Partially fertile & $23-5 \mathrm{~B}, 23-7 \mathrm{~A}$ \\
5 & F & Fertile & $4-5 \mathrm{C}, 4-7 \mathrm{~A}$, \\
6 & FF & Highly / fully Fertile & $4-3 \mathrm{~A}, 14-4 \mathrm{C}, 19-3 \mathrm{C}, 14-4 \mathrm{~A}$ \\
\hline
\end{tabular}

Note: Pollen sterility status was classified as, CS: (0\%), S: (1-9\%), PS: (10-29\%), PF: (30-69\%): F: (70-79\%), FF: ( $\geq 80 \%$ and above).

To reduce the breeding cycles to develop glutinous rice lines, the developed mutant glutinous maintainer lines (as the male parent) were used to hybridize with CMS line 209A (as female parent) to produce $F_{1}$ hybrids, and then the $F_{1}$ hybrids were backcrossed with mutant lines. Molecular 
marker-assisted selection (MAS) was used to select the homozygous plants in the $\mathrm{BC}_{1} \mathrm{~F}_{1}$ and $\mathrm{CMS}$ plants were selected and again backcrossed with mutant lines and two homozygous $\mathrm{BC}_{2} \mathrm{~F}_{1} \mathrm{CMS}$ lines (GX-B1, GX-B6) were obtained with no genetic segregation and increased yield and waxy-grain phenotype (Figure 7c), which will be used for the further breeding of hybrid glutinous rice.

\subsection{Pollen Protein Identification}

A total 25 spots in both genotypes were exercised and ultimately 16 spots were successfully identified, and proteins associated with pollen development (Table 6). The important proteins Putative acetyl-CoA synthetase and isoamylase were upregulated in both lines which clearly showed that these proteins have important role in CMS and control of AC in rice (Table 6).

Table 6. Rice pollen protein identified by peptide mass fingerprinting.

\begin{tabular}{|c|c|c|c|c|c|c|}
\hline \multirow{2}{*}{ Sr. No. } & \multirow{2}{*}{ Matched Protein } & \multirow{2}{*}{ Organism } & \multirow{2}{*}{ Accession No. } & \multirow{2}{*}{$\mathrm{Mr} / \mathrm{pl}^{*}$} & \multicolumn{2}{|c|}{ Spot Regulation } \\
\hline & & & & & GX-B1 & $4-2 \mathrm{~A}$ \\
\hline 1 & 20S proteasome beta 4 subunit & O. sativa & Q9LST6 & $23.6 / 5.42$ & + & - \\
\hline 2 & Putative RNA-binding protein & O. sativa & Q852C0 & $97.3 / 9.34$ & + & - \\
\hline 3 & Putative berberine bridge enzyme & O. sativa & Q84pv5 & $60.10 / 6.0$ & + & - \\
\hline 4 & Putative mitochondrial $\mathrm{NAD}^{+}$-dependent malic enzyme & O. sativa & Q9FVY8 & $57.34 / 8.2$ & - & + \\
\hline 5 & Putative calcium-binding protein annexin & O. sativa & Q84Q48 & $35.5 / 9.44$ & + & - \\
\hline 6 & UDP-glucuronic acid decarboxylase & O. sativa & Q8W3J0 & $39.5 / 7.16$ & - & + \\
\hline 7 & Putative phosphoribosyl pyrophosphate synthase & O. sativa & Q8S2E5 & $44.17 / 6.9$ & + & ++ \\
\hline 8 & Putative RNA binding protein & O. sativa & Q7XC34 & $48.4 / 5.21$ & - & + \\
\hline 9 & $\begin{array}{l}\mathrm{H}^{+} \text {-transporting two-sector ATPase alpha } \\
\text { chain-rice mitochondria }\end{array}$ & O. sativa & P15998 & $55.53 / 7.9$ & + & - \\
\hline 10 & Glucose-1-phosphate adenylyltransferase large subunit 3 & O. sativa & Q688T8 & $56.2 / 6.48$ & - & + \\
\hline 11 & Putative membrane-associated salt-inducible protein & O. sativa & Q8W2V6 & $78.02 / 9.2$ & + & - \\
\hline 12 & Putative leucine-rich repeat protein & O. sativa & Q6I5I5 & $29.58 / 9.6$ & ++ & + \\
\hline 13 & Putative acetyl-CoA synthetase & O. sativa & Q6H798 & $78.5 / 5.69$ & + & ++ \\
\hline 14 & Putative lipoamide dehydrogenase & O. sativa & Q94GU7 & $58.8 / 6.35$ & - & + \\
\hline 15 & Isoamylase (fragrant) & O. sativa & DOTZF0 & $82.1 / 5.46$ & ++ & + \\
\hline 16 & DNA binding protein & O. sativa & Q40691 & $33.0 / 8.96$ & + & + \\
\hline
\end{tabular}

The identified proteins have various biological functions based on known functions from known functions from the European Bioinformatics Institute (EMBL-EBI) and literature. The protein spots related to GX-B1 were cellular protein catabolic process, RNA-binding, oxidoreductase activity, calcium-dependent phospholipid binding, nucleoside metabolic process, photosystem I assembly, acetyl-CoA biosynthetic process from acetate and amylopectin and their beta-limit dextrins (highly expressed). The protein spots of 4-2A were related to malate metabolic process (highly expressed), $\mathrm{NAD}^{+}$binding, nucleoside metabolic process, RNA binding, starch biosynthetic process, acetyl-CoA biosynthetic process from acetate (highly expressed) and amylopectin and their beta-limit dextrins.

\section{Discussion}

CRISPR/Cas9 is an emerging genome editing technology developed in past few years with high specificity and editing efficiency. Relative to ZFNs [68] and TALENs [69,70], CRISPR/Cas9 is simple and flexible and only one gRNA and one nuclease (Cas9) are needed to achieve the mutations in the DNA sequence of the target gene. Current research focuses on the development of CRISPR/Cas9 technology and specific gene knockouts.

Breeding for consumer-preferred grain yield and quality have thus become a major goal for breeding programs and in the last few decades, the classical, mutational, and molecular breeding approaches have brought about tremendous increase in rice productivity with the development of novel rice varieties for food security considerations. The improved living standards and fast economic growth are shifting public attention toward quality characteristics such as, nutrition, flavor, appearance, and cooking which are linked to starch physical properties. With the development of latest gene editing technologies such as CRISPR/Cas9, many yield related quantitative trait loci (QTLs) has been edited and their functions have been explored in different verities [37]. In the rice grain endosperm, starch is 
the major component consisting of a linear polysaccharide amylose which determines the cooking and eating quality of rice. Cooking of high AC (25-33\%) verities results in separated, dry and firm rice grains, becoming hard after cooling while glutinous rice with low AC (5-20\%) is especially sticky and soft when cooked [71]. The improvement of maintainer line in hybrid rice breeding system is most inevitable to achieve target traits. In China, the indica hybrids considered low quality owing to high $\mathrm{AC}$ that makes them hard and dry when cooked. The breeding for low AC and improved grain quality and yield is a major objective of breeders.

In this study the CRISPR/Cas9 construct with 20-nt target sequence for the sgRNA was carefully designed with high GC content and low off-target score and the Wx and TGW6 gene with expectation to produce a null mutation were edited. The schematic representation of whole procedure of generation and analysis of targeted mutated plants was described in Figure S6. The goal of this study was to develop a high yielding CMS rice line with low amylose content to facilitate the hybrid rice breeding program and proteins from anthers of maintainer and CMS line were also identified. We sequenced the Wx and TGW6 gene and confirmed that 209B contains both genes (Figure S7). Four targets were designed in the exon regions of $W x$ and TGW6 gene, the corresponding promoters were OsU6a, OsU6b, OsU6c, and OsU3m and Agrobacterium tumefaciens based transformations was successfully achieved with the CRISPR/Cas9 cassette and mutations in the target regions were analyzed by sanger sequencing by decoding it using online DSDecodeM tool. The results of this study indicate that the CRISPR/Cas9 gene editing technology can successfully edit rice targeting DNA sequences with high efficiency and multiple mutations can be generated at the same target site, and base deletion or insertion occurs before the target site PAM.

The total mutation frequency was up to $90 \%$, wherein homozygous mutations were about $28 \%$, which indicate that the CRISPR/Cas9 editing facilitates homozygous mutations in the $\mathrm{T}_{0}$ generation (Table 1). The previous studies showed that the CRISPR/Cas9 induced the homozygous mutations in $\mathrm{T}_{0}$ generation and mutations mainly take place in transformed calli cells [72]. The expression level of targeted genes was lower in mutant lines than WT (Figure 6). The off-target mutations were not detected for all targets (Table S3). The comparison of $\mathrm{T}_{0}$ and $\mathrm{T}_{1}$ generations showed that the mutation frequency of homozygotes was stably inherited regardless of whether T-DNA is present. The conserved amino acid sequence was totally changed in mutant plants and mutant plants showed divergence to WT in amino acid sequence alignment (Figure 5).

The glutinous rice lines were obtained, and all mutant lines seeds showed low AC decreased from $18.2 \%$ to $1.7 \%$ and homozygous mutant lines showed less percentage of $\mathrm{AC}$ than heterozygous and bi-allelic mutants (Table 2). It is reported that the $W x$ gene also affect the GC and GT of rice [22,73] and our results showed an increase in GC from $58.65 \mathrm{~mm}$ to $138.62 \mathrm{~mm}$ and decrease in GT from 5.67 ASV to $3.12 \mathrm{ASV}$, while there was no effect on total SC (Table 2). The GW was increased from $21.1 \mathrm{~g}$ to $240.8 \mathrm{~g}$ (Table 3), while there was no effect on PH, NOP, FLL, FLW, PL, GPS, and SSR (Table 4). The cross-section analysis by electron microscope showed that endosperm of mutant grains was shrunken corresponding to their WT. The T-DNA free lines were obtained to address the social values of laws about genetically modified (GM) foods by selecting the transgene free lines by self-pollination in the $T_{1}$ and $T_{2}$ generations (Figure 7). Our results showed that the $T_{1}$ mutant lines were re-edited while mutations were inherited and stable in $\mathrm{T}_{2}$ generation (Figure 8 ). The $\mathrm{T}_{0}$ lines are frequently difficult to predict which suggests that the mutations in $\mathrm{T}_{0}$ generations are not stable but the mutations in $\mathrm{T}_{1}$ generations transmitted stably to later generations. These results are consistent with previous reports that the editing site of the $\mathrm{T}_{1}$ generation mutant plant target sequence may also have a sequence recognized by the gRNA target, resulting in re-editing, which makes the $\mathrm{T}_{1}$ generation unpredicted which can stabilize in later generations [74]. Together, these results clearly demonstrate that CRISPR/Cas9-induced gene mutations can be stably transmitted to subsequent generations.

The shape of pollen grains and staining patterns in male sterility inducing cytoplasm and sterility maintaining nuclear genes are influenced by the pollen abortion stage related to nuclear stage [75]. Mutant maintainer lines were assessed for pollen fertility status and results showed that pollen fertility 
rate was randomly distributed and six genotypes were found sterile having pollen fertility 0-9\%, two genotypes PS with 10-29\% pollen fertility, two genotypes were recorded PF which is $12.5 \%$ of total and four genotypes were identified as $\mathrm{CF}$ and two were $\mathrm{F}$ as these genotypes had above $80 \%$ pollen and spikelet fertility which is $37.50 \%$ of the total genotypes (Table 5). The developed maintainer lines were crossed with CMS line to develop $F_{1}$ and after subsequent backcrossing glutinous CMS line was achieved.

The CMS lines has been widely used in hybrid rice production, but the molecular mechanism of CMS remains poor understood. The protein identification tool is a powerful tool to study anther development and pollen production in plants [76-79]. The CMS is different plant species are cause by a specific ORF containing chimeric genes in mitochondrial genome [80] with rare similarity but sharing same male gamete abortion phenomenon [81]. The mitochondrial amplification events suggest an increased demand for energy during pollen development [82] but lowered ATP production was also observed in some CMS flowers [81,83]. In this study the proteins identified in maintainer and CMS line helped to understand the molecular mechanism of rice male sterility. Sixteen proteins were identified between sterile and maintainer anthers (Table 6). The identified proteins have potential roles in anther and pollen development and may help to clarify the mechanism of male sterility in rice.

The proteins of CMS line and GX4-2 maintainer mutant line anthers were separated by two-dimensional electrophoresis and SDS-PAGE as the second. The silver stained proteins were analyzed using Image Master 2D software. The identified proteins were, $20 \mathrm{~S}$ proteasome beta 4 subunit, putative RNA-binding protein, Putative berberine bridge enzyme (BBE), putative mitochondrial $\mathrm{NAD}^{+}$-dependent malic enzyme, Putative calcium-binding protein annexin, UDP-glucuronic acid decarboxylase, putative phosphoribosyl pyrophosphate synthase, putative RNA binding protein (RBP), $\mathrm{H}^{+}$-transporting two-sector ATPase alpha chain-rice mitochondria, glucose-1-phosphate adenylyltransferase large subunit 3, putative membrane-associated salt-inducible protein, putative leucine-rich repeat protein, putative acetyl-CoA synthetase (ACOS), putative lipoamide dehydrogenase, Isoamylase (fragrant), and DNA binding protein (Table 6). These proteins are closely associated with metabolism, protein biosynthesis, transcription, signal transduction and many other activities which are important in cell activities and essential to pollen development.

Dysfunctions of mitochondria in the pollen caused CMS in plants and several other mitochondrion regions have been identified associated with CMS [84]. ATP synthase $\beta$-subunit helps to fulfill the demand of energy for respiratory function and cellular energy to develop male gametophyte also observed in mitochondria [85], and defective $\beta$-subunit resulted non-functional pollens and abnormal anther development [84]. The 20S proteasome is the proteolytic complex actively involved in removing abnormal proteins with several biological functions [86], while RBP is involved to regulate transcriptional and post-transcriptional levels to control the gene expression. Plants respond to pathogen infection with rapid reprogramming of gene expression and loss of function of RBP showed enhanced resistance to pathogens [77]. Biochemical and biological function of BBE are unexplored [87]. Plant annexins regulate diverse aspects of plant development, stress responses and growth [88]. ACOS played role in plastids and in several metabolic pathways [89] and has significant role in anther development $[90,91]$. The ACOS in anther prevent the conversion of pyruvate into acetyl-CoA which leads to pollen sterility. The degeneration and formation of various tissues during pollen development needs high energy for key biosynthetic intermediates. Isoamylase in combination with pullulanase plays a predominant role in amylopectin synthesis and also essential for the construction of the amylopectin multiple-cluster structure by removing the excessive branches to avoid interference with the formation of double helices of the cluster chains of amylopectin and crystallization of starch in the endosperm. These proteins or enzymes are involved in multiple physiological and biochemical reactions such as carbon metabolism and starch synthesis, as well as signal transduction and protein expression regulation [92].

In short, the increase yield and reduction of AC are valuable parameters in crop breeding and CRISPR/Cas9 is excellent technology to achieve targeted mutations in genes. In this study the rice 
maintainer line and new CMS lines were developed with increased yield and improved quality while maintaining all agronomic traits. We also took precautionary approach and produced T-DNA-free plants to avoid foreign bacterial DNA integration and bypass GMO rules. The most likely off-target effects were analyzed and Cas 9 free plants were selected for food safety assessments and it was ensured that the other plant traits were not affected. In our work, we improved existing traits by directly rewriting the plant genetic code without any cutting and pasting genes from animals or bacteria into rice plants. Our study provides some insights to study the gene functions and generation of new rice CMS lines with increased yield and improved quality without compromising on nutritional value to facilitate the hybrid breeding programs of rice to develop elite crop verities. This study is the first example to develop rice CMS lines with increased yield and low AC and the protein identification in mutant rice maintainer and CMS line which will be the source material for further breeding of hybrid glutinous rice verities in short period. The identified proteins in anther of maintainer and CMS lines provide the insights to the actual mechanism underlying in sterility of rice lines. The study showed the genetic mutations are not only helpful to improve the plant characteristics, they also help in understanding the mechanisms underlying the biochemical behavior changes in cell of the plants.

\section{Conclusions}

The CRISPR/Cas9 technology induces fastest changes to plant genome than other molecular approaches and mutations passed to the next generations without any rewriting or emendations. Different types of mutations were achieved for both genes and a mutant library was generated which laid an important material basis for further high-yield and stable hybrid breeding of rice. This study provides an important theoretical and practical significance and reference for the rapid creation of excellent rice germplasm with important application value such as rice quality, and male sterility, and is expected to provide a safe and efficient new way for rice germplasm resources innovation. This study applied a proteomic approach to identify the regulating proteins of a CMS and mutant maintainer rice line and it is concluded that pollen development in different genetic material is associated with the differential expression of several proteins. These results collectively suggested that the knowledge of these parameters in rice breeding may be further applied as criteria to develop rice CMS lines. The new germplasm with important application value was obtained which laid an important material basis for further breeding program to facilitate the rice breeding to improve yield and quality.

Supplementary Materials: The following are available online at http:/ / www.mdpi.com/2073-4395/8/12/290/s1, Figure S1: Schematic representation of secondary structures of both sgRNAs used in this experiment. (a) structure both sgRNA's for Wx targets and (b) structure of both sgRNA's for TGW6 targets. The stem loop sgRNA secondary structure was predicted by online tool (http:/ / crispr.hzau.edu.cn/cgi-bin/CRISPR/CRISPR); Figure S2: Isolation of the binary plasmids and sgRNA intermediate plasmids; Figure S3: Sequences of the sgRNA vectors and those of the expression cassettes; Figure S4: sgRNA expression cassette procedure by overlapping PCR containing a target sequence. The chimeric primers with target sequence strands are given in additional file 3 . The first PCR is carried out in two separated reactions with U-F/U\#T\#- and gRT\#+/gR-R primer pair, U\# indicates a given promoter, and $\mathrm{TH}+$ and $\mathrm{T \# -}$ indicate forward and reverse strands of a target sequence; Figure S5: Illustration for transformation of E. coli; Figure S6: Schematic diagram of the procedure for CRISPR/Cas9 based generation of mutant plants and analysis of target regions. The targets were selected using CRISPR-GE online web-based tool and expression cassette was constructed by using overlapping PCR and inserted into a binary vector. Agrobacterium mediated transformation was performed and $\mathrm{T}_{0}$ plants were regenerated and sequencing was performed, and later generations were produced by self-pollination and genotyping was performed by using target specific primers in $\mathrm{T}_{1}$ and $\mathrm{T}_{2}$ generations. The phenotypic data of mutant and wild type plants were recorded and further analyzed. Pollen fertility analysis and protein identification was also performed; Figure S7: Sequence alignment of the (a) Wx and (b) TGW6 gene in reference genome and 209B maintainer line. The SNPs between reference genome and 209B are indicated in red box; Table S1: Efficiency score and positions of four targets; Table S2: List of primers used in the study; Table S3: Detection of mutations on the putative off-target sites; Table S4: Pollen fertility status of $\mathrm{F}_{1}$ lines. 
Author Contributions: Conceptualization, Y.H. and D.L.; Data curation, B.U., G.N. and F.L.; Formal analysis, Y.H., D.L., B.U. and N.Z.; Funding acquisition, R.L.; Investigation, D.L., B.U. and N.Z.; Methodology, H.Y., D.L. and B.U.; Project administration, R.L.; Resources, R.L.; Software, B.U.; Supervision, R.L.; Validation, F.L. and R.L.; Visualization, G.N., F.L. and R.L.; Writing—original draft. D.L., B.U. and G.N.; Writing一review \& editing, R.L.

Funding: This research was funded by the Key Technology Research and Development Program Guike, Guangxi (Guike AB16380066; Guike AB16380093).

Acknowledgments: We would like to thank Li Zhihua and Qin Baoxiang for the helpful discussion and invaluable comments to make this research meaningful. We are highly grateful to Liu Yaoguang for providing us the vector and promoters for the experiment.

Conflicts of Interest: The authors declare that they have no competing interests.

Accession Numbers: Sequence data from this article can be found in the GenBank data library under accession numbers GenBank: KR029105, KR029107, KR029108 and KR559259 for the sgRNA intermediate plasmids and GenBank: KR029109 for the CRISPR/Cas9 binary vector.

\section{References}

1. Birla, D.S.; Malik, K.; Sainger, M.; Chaudhary, D.; Jaiwal, R.; Jaiwal, P.K. Progress and challenges in improving the nutritional quality of rice (Oryza sativa L.). Crit. Rev. Food Sci. Nutr. 2017, 57, 2455-2481. [CrossRef] [PubMed]

2. Pérez-Montaño, F.; Alías-Villegas, C.; Bellogín, R.; Del Cerro, P.; Espuny, M.; Jiménez-Guerrero, I.; López-Baena, F.J.; Ollero, F.; Cubo, T. Plant growth promotion in cereal and leguminous agricultural important plants: From microorganism capacities to crop production. Microbiol. Res. 2014, 169, 325-336. [CrossRef] [PubMed]

3. Milovanovic, V.; Smutka, L. Asian Countries in the Global Rice Market. Acta Univ. Agric. Silvic. Mendel. Brun. 2017, 65, 679-688. [CrossRef]

4. Hsu, Y.C.; Tseng, M.C.; Wu, Y.P.; Lin, M.Y.; Wei, F.J.; Hwu, K.K.; Hsing, Y.I.; Lin, Y.R. Genetic factors responsible for eating and cooking qualities of rice grains in a recombinant inbred population of an inter-subspecific cross. Mol. Breed. 2014, 34, 655-673. [CrossRef] [PubMed]

5. Yuan, L.; Tang, C. Retrospect, current status and prospect of hybrid rice. Rice in China 1999, 4, 3-6.

6. Cheng, S.H.; Zhuang, J.Y.; Fan, Y.Y.; Du, J.H.; Cao, L.Y. Progress in research and development on hybrid rice: a super-domesticate in China. Ann. Bot. 2007, 100, 959-966. [CrossRef] [PubMed]

7. Sharma, S.; Singh, S.; Nandan, R.; Kumar, M. Identification of restorers and maintainers for CMS lines of rice (Oryza sativa L.). Ind. J. Plant Gen. Res. 2012, 25, 186-188. [CrossRef]

8. Umesh, S.; Lal, J.; Kumar, H. Isolation and evaluation of restorers and examining possibility of developing new version of CMS lines for upland rainfed rice hybrids. Environ. Ecol. 2012, 30, 872-876.

9. Xing, Y.; Zhang, Q. Genetic and molecular bases of rice yield. Annu. Rev. Plant Biol. 2010, 61, 421-442. [CrossRef]

10. You, A.; Lu, X.; Jin, H.; Ren, X.; Liu, K.; Yang, G.; Yang, H.; Zhu, L.; He, G. Identification of quantitative trait loci across recombinant inbred lines and testcross populations for traits of agronomic importance in rice. Genetics 2006, 172, 1287-1300. [CrossRef]

11. Wani, A.A.; Singh, P.; Shah, M.A.; Schweiggert-Weisz, U.; Gul, K.; Wani, I.A. Rice starch diversity: Effects on structural, morphological, thermal, and physicochemical properties-A review. Compr. Rev. Food Sci. Food Saf. 2012, 11, 417-436. [CrossRef]

12. Wang, Z.Y.; Zheng, F.Q.; Shen, G.Z.; Gao, J.P.; Snustad, D.P.; Li, M.G.; Zhang, J.L.; Hong, M.M. The amylose content in rice endosperm is related to the post-transcriptional regulation of the waxy gene. Plant J. 1995, 7, 613-622. [CrossRef] [PubMed]

13. Isshiki, M.; Morino, K.; Nakajima, M.; Okagaki, R.J.; Wessler, S.R.; Izawa, T.; Shimamoto, K. A naturally occurring functional allele of the rice waxy locus has a GT to TT mutation at the $5^{\prime}$ splice site of the first intron. Plant J. 1998, 15, 133-138. [CrossRef] [PubMed]

14. Sano, Y. Differential regulation of waxy gene expression in rice endosperm. Theor. Appl. Genet. 1984, 68, 467-473. [CrossRef] [PubMed]

15. Larkin, P.D.; Park, W.D. Association of waxy gene single nucleotide polymorphisms with starch characteristics in rice (Oryza sativa L.). Mol. Breed. 2003, 12, 335-339. [CrossRef] 
16. Bligh, H.F.J.; Larkin, P.D.; Roach, P.S.; Jones, C.A.; Fu, H.; Park, W.D. Use of alternate splice sites in granule-bound starch synthase mRNA from low-amylose rice varieties. Plant Mol. Biol. 1998, 38, 407-415. [CrossRef]

17. Sato, H.; Suzuki, Y.; Sakai, M.; Imbe, T. Molecular characterization of Wx-mq, a novel mutant gene for low-amylose content in endosperm of rice (Oryza sativa L.). Breed. Sci. 2002, 52, 131-135. [CrossRef]

18. Bergman, C.; Delgado, J.; McClung, A.; Fjellstrom, R. An improved method for using a microsatellite in the rice waxy gene to determine amylose class. Cereal Chem. 2001, 78, 257-260. [CrossRef]

19. Inukai, T.; Sako, A.; Hirano, H.Y.; Sano, Y. Analysis of intragenic recombination at wx in rice: correlation between the molecular and genetic maps within the locus. Genome 2000, 43, 589-596. [CrossRef]

20. Ma, X.; Zhang, Q.; Zhu, Q.; Liu, W.; Chen, Y.; Qiu, R.; Wang, B.; Yang, Z.; Li, H.; Lin, Y. A robust CRISPR/Cas9 system for convenient, high-efficiency multiplex genome editing in monocot and dicot plants. Mol. Plant. 2015, 8, 1274-1284. [CrossRef]

21. Terada, R.; Nakajima, M.; Isshiki, M.; Okagaki, R.J.; Wessler, S.R.; Shimamoto, K. Antisense waxy genes with highly active promoters effectively suppress waxy gene expression in transgenic rice. Plant Cell Physiol. 2000, 41, 881-888. [CrossRef] [PubMed]

22. Liu, Q.; Wang, Z.; Chen, X.; Cai, X.; Tang, S.; Yu, H.; Zhang, J.; Hong, M.; Gu, M. Stable inheritance of the antisense Waxy gene in transgenic rice with reduced amylose level and improved quality. Transgenic Res. 2003, 12, 71-82. [CrossRef] [PubMed]

23. Liu, Q.; Yu, H.; Chen, X.; Cai, X.; Tang, S.; Wang, Z.; Gu, M. Field performance of transgenic indica hybrid rice with improved cooking and eating quality by down-regulation of Wx gene expression. Mol. Breed. 2005, 16, 199-208. [CrossRef]

24. Itoh, K.; Ozaki, H.; Okada, K.; Hori, H.; Takeda, Y.; Mitsui, T. Introduction of Wx transgene into rice wx mutants leads to both high-and low-amylose rice. Plant Cell Physiol. 2003, 44, 473-480. [CrossRef] [PubMed]

25. Shomura, A.; Izawa, T.; Ebana, K.; Ebitani, T.; Kanegae, H.; Konishi, S.; Yano, M. Deletion in a gene associated with grain size increased yields during rice domestication. Nat. Genet. 2008, 40, 1023. [CrossRef] [PubMed]

26. Weng, J.; Gu, S.; Wan, X.; Gao, H.; Guo, T.; Su, N.; Lei, C.; Zhang, X.; Cheng, Z.; Guo, X. Isolation and initial characterization of GW5, a major QTL associated with rice grain width and weight. Cell Res. 2008, 18, 1199. [CrossRef]

27. Ishimaru, K.; Hirotsu, N.; Madoka, Y.; Murakami, N.; Hara, N.; Onodera, H.; Kashiwagi, T.; Ujiie, K.; Shimizu, B.-i.; Onishi, A. Loss of function of the IAA-glucose hydrolase gene TGW6 enhances rice grain weight and increases yield. Nat. Genet. 2013, 45, 707. [CrossRef]

28. Fan, C.; Xing, Y.; Mao, H.; Lu, T.; Han, B.; Xu, C.; Li, X.; Zhang, Q. GS3, a major QTL for grain length and weight and minor QTL for grain width and thickness in rice, encodes a putative transmembrane protein. Theor. Appl. Genet. 2006, 112, 1164-1171. [CrossRef]

29. Li, Y.; Fan, C.; Xing, Y.; Jiang, Y.; Luo, L.; Sun, L.; Shao, D.; Xu, C.; Li, X.; Xiao, J. Natural variation in GS5 plays an important role in regulating grain size and yield in rice. Nat. Genet. 2011, 43, 1266-1269. [CrossRef]

30. Song, X.J.; Huang, W.; Shi, M.; Zhu, M.Z.; Lin, H.X. A QTL for rice grain width and weight encodes a previously unknown RING-type E3 ubiquitin ligase. Nat. Genet. 2007, 39, 623. [CrossRef]

31. Wang, S.; Wu, K.; Yuan, Q.; Liu, X.; Liu, Z.; Lin, X.; Zeng, R.; Zhu, H.; Dong, G.; Qian, Q. Control of grain size, shape and quality by OsSPL16 in rice. Nat. Genet. 2012, 44, 950. [CrossRef] [PubMed]

32. Hu, Z.; He, H.; Zhang, S.; Sun, F.; Xin, X.; Wang, W.; Qian, X.; Yang, J.; Luo, X. A Kelch motif-containing serine/threonine protein phosphatase determines the large grain QTL trait in rice. J. Integr. Plant Biol. 2012, 54, 979-990. [CrossRef] [PubMed]

33. Qi, P.; Lin, Y.S.; Song, X.J.; Shen, J.B.; Huang, W.; Shan, J.X.; Zhu, M.Z.; Jiang, L.; Gao, J.P.; Lin, H.X. The novel quantitative trait locus GL3. 1 controls rice grain size and yield by regulating Cyclin-T1; 3. Cell Res. 2012, 22, 1666-1680. [CrossRef] [PubMed]

34. Zhang, X.; Wang, J.; Huang, J.; Lan, H.; Wang, C.; Yin, C.; Wu, Y.; Tang, H.; Qian, Q.; Li, J. Rare allele of OsPPKL1 associated with grain length causes extra-large grain and a significant yield increase in rice. Proc. Natl. Acad. Sci. USA 2012, 109, 21534-21539. [CrossRef] [PubMed]

35. Wang, S.; Li, S.; Liu, Q.; Wu, K.; Zhang, J.; Wang, S.; Wang, Y.; Chen, X.; Zhang, Y.; Gao, C. The OsSPL16-GW7 regulatory module determines grain shape and simultaneously improves rice yield and grain quality. Nat. Genet. 2015, 47, 949. [CrossRef] [PubMed] 
36. Si, L.; Chen, J.; Huang, X.; Gong, H.; Luo, J.; Hou, Q.; Zhou, T.; Lu, T.; Zhu, J.; Shangguan, Y. OsSPL13 controls grain size in cultivated rice. Nat. Genet. 2015, 47, 447. [CrossRef] [PubMed]

37. Zhang, H.; Zhang, J.; Lang, Z.; Botella, J.R.; Zhu, J.K. Genome editing-Principles and applications for functional genomics research and crop improvement. Crit. Rev. Plant Sci. 2017, 36, 291-309. [CrossRef]

38. Li, M.; Li, X.; Zhou, Z.; Wu, P.; Fang, M.; Pan, X.; Lin, Q.; Luo, W.; Wu, G.; Li, H. Reassessment of the four yield-related genes Gn1a, DEP1, GS3, and IPA1 in rice using a CRISPR/Cas9 system. Front. Plant Sci. 2016, 7, 377. [CrossRef]

39. Xu, R.; Yang, Y.; Qin, R.; Li, H.; Qiu, C.; Li, L.; Wei, P.; Yang, J. Rapid improvement of grain weight via highly efficient CRISPR/Cas9-mediated multiplex genome editing in rice. J. Genet. Genom. 2016, 43, 529-532. [CrossRef]

40. Bortesi, L.; Fischer, R. The CRISPR/Cas9 system for plant genome editing and beyond. Biotechnol. Adv. 2015, 33, 41-52. [CrossRef]

41. Baltes, N.J.; Gil-Humanes, J.; Cermak, T.; Atkins, P.A.; Voytas, D.F. DNA replicons for plant genome engineering. Plant Cell. 2014, 26, 161-163. [CrossRef] [PubMed]

42. Miglani, G.S. Genome editing in crop improvement: Present scenario and future prospects. J. Crop Improv. 2017, 31, 453-559. [CrossRef]

43. Feng, Z.; Zhang, B.; Ding, W.; Liu, X.; Yang, D.L.; Wei, P.; Cao, F.; Zhu, S.; Zhang, F.; Mao, Y. Efficient genome editing in plants using a CRISPR/Cas system. Cell Res. 2013, 23, 1229-1232. [CrossRef] [PubMed]

44. Voytas, D.F.; Gao, C. Precision genome engineering and agriculture: opportunities and regulatory challenges. PLoS Biol. 2014, 12, e1001877. [CrossRef] [PubMed]

45. Belhaj, K.; Chaparro-Garcia, A.; Kamoun, S.; Patron, N.J.; Nekrasov, V. Editing plant genomes with CRISPR/Cas9. Curr. Opin. Biotechnol. 2015, 32, 76-84. [CrossRef] [PubMed]

46. Weeks, D.P.; Spalding, M.H.; Yang, B. Use of designer nucleases for targeted gene and genome editing in plants. Plant Biotechnol. J. 2016, 14, 483-495. [CrossRef] [PubMed]

47. Doudna, J.A.; Charpentier, E. The new frontier of genome engineering with CRISPR-Cas9. Science 2014, 346, 1258096. [CrossRef]

48. Khatodia, S.; Bhatotia, K.; Passricha, N.; Khurana, S.; Tuteja, N. The CRISPR/Cas genome-editing tool: Application in improvement of crops. Front. Recent Dev. Plant Sci. 2016, 7, 506. [CrossRef]

49. Nekrasov, V.; Staskawicz, B.; Weigel, D.; Jones, J.D.; Kamoun, S. Targeted mutagenesis in the model plant Nicotiana benthamiana using Cas9 RNA-guided endonuclease. Nat. Biotechnol. 2013, 31, 691. [CrossRef]

50. Jiang, W.; Zhou, H.; Bi, H.; Fromm, M.; Yang, B.; Weeks, D.P. Demonstration of CRISPR/Cas9/sgRNA-mediated targeted gene modification in Arabidopsis, tobacco, sorghum and rice. Nucleic Acids Res. 2013, 41, e188. [CrossRef]

51. Miao, J.; Guo, D.; Zhang, J.; Huang, Q.; Qin, G.; Zhang, X.; Wan, J.; Gu, H.; Qu, L.J. Targeted mutagenesis in rice using CRISPR-Cas system. Cell Res. 2013, 23, 1233-1236. [CrossRef]

52. Shan, Q.; Wang, Y.; Li, J.; Zhang, Y.; Chen, K.; Liang, Z.; Zhang, K.; Liu, J.; Xi, J.J.; Qiu, J.L. Targeted genome modification of crop plants using a CRISPR-Cas system. Nat. Biotechnol. 2013, 31, 686-688. [CrossRef]

53. Wang, Y.; Cheng, X.; Shan, Q.; Zhang, Y.; Liu, J.; Gao, C.; Qiu, J.L. Simultaneous editing of three homoeoalleles in hexaploid bread wheat confers heritable resistance to powdery mildew. Nat. Biotechnol. 2014, 32, 947. [CrossRef] [PubMed]

54. Char, S.N.; Neelakandan, A.K.; Nahampun, H.; Frame, B.; Main, M.; Spalding, M.H.; Becraft, P.W.; Meyers, B.C.; Walbot, V.; Wang, K.; et al. An Agrobacterium-delivered CRISPR/Cas9 system for high-frequency targeted mutagenesis in maize. Plant Biotech. J. 2017, 15, 257-268. [CrossRef]

55. Butler, N.M.; Atkins, P.A.; Voytas, D.F.; Douches, D.S. Generation and inheritance of targeted mutations in potato (Solanum tuberosum L.) using the CRISPR/Cas system. PLoS ONE 2015, 10, e0144591. [CrossRef] [PubMed]

56. Pan, C.; Ye, L.; Qin, L.; Liu, X.; He, Y.; Wang, J.; Chen, L.; Lu, G. CRISPR/Cas9-mediated efficient and heritable targeted mutagenesis in tomato plants in the first and later generations. Sci. Rep. 2016, 6, 24765. [CrossRef] [PubMed]

57. Ma, X.; Liu, Y.G. CRISPR/Cas9-based multiplex genome editing in monocot and dicot plants. Curr. Protoc. Mol. Biol. 2016, 115, 31.6.1-31.6.21. [CrossRef]

58. Moore, D.; Dowhan, D. Purification and concentration of DNA from aqueous solutions. Curr. Protoc. Mol. Biol. 2002, 59, 2.1.1-2.1.10. [CrossRef] 
59. Hiei, Y.; Ohta, S.; Komari, T.; Kumashiro, T. Efficient transformation of rice (Oryza sativa L.) mediated by Agrobacterium and sequence analysis of the boundaries of the T-DNA. Plant J. 1994, 6, 271-282. [CrossRef]

60. Kang, H.G.; Park, S.; Matsuoka, M.; An, G. White-core endosperm floury endosperm-4 in rice is generated by knockout mutations in the C4-type pyruvate orthophosphate dikinase gene (OsPPDKB). Plant J. 2005, 42, 901-911. [CrossRef]

61. Livak, K.J.; Schmittgen, T.D. Analysis of relative gene expression data using real-time quantitative PCR and the $2^{-\Delta \Delta C T}$ method. Methods 2001, 25, 402-408. [CrossRef] [PubMed]

62. Cagampang, G.B.; Perez, C.M.; Juliano, B.O. A gel consistency test for eating quality of rice. J. Sci. Food Agric. 1973, 24, 1589-1594. [CrossRef] [PubMed]

63. Little, R.R. Differential effect of dilute alkali on 25 varieties of milled white rice. Cereal Chem. 1958, 35, 111-126.

64. Virmani, S.S. Hybrid Rice Breeding Manual; International Rice Research Institute: Laguna, Philippines, 1997.

65. Sarhadi, E.; Bazargani, M.M.; Sajise, A.G.; Abdolahi, S.; Vispo, N.A.; Arceta, M.; Nejad, G.M.; Singh, R.K.; Salekdeh, G.H. Proteomic analysis of rice anthers under salt stress. Plant Physiol. Biochem. 2012, 58, 280-287. [CrossRef] [PubMed]

66. Laemmli, U.K. Cleavage of structural proteins during the assembly of the head of bacteriophage T4. Nature 1970, 227, 680-685. [CrossRef] [PubMed]

67. Mathesius, U.; Imin, N.; Chen, H.; Djordjevic, M.A.; Weinman, J.J.; Natera, S.H.; Morris, A.C.; Kerim, T.; Paul, S.; Menzel, C.; et al. Evaluation of proteome reference maps for cross-species identification of proteins by peptide mass fingerprinting. Proteomics 2002, 2, 1288-1303. [CrossRef]

68. Dreier, B.; Beerli, R.R.; Segal, D.J.; Flippin, J.D.; Barbas, I. Development of zinc finger domains for recognition of the $5^{\prime}$-ANN-3' family of DNA sequences and their use in the construction of artificial transcription factors. J. Biol. Chem. 2001, 276, 29466-29478. [CrossRef] [PubMed]

69. Tesson, L.; Usal, C.; Ménoret, S.; Leung, E.; Niles, B.J.; Remy, S.; Santiago, Y.; Vincent, A.I.; Meng, X.; Zhang, L.; et al. Knockout rats generated by embryo microinjection of TALENs. Nat. Biotechnol. 2011, $29,695$. [CrossRef]

70. Huang, P.; Xiao, A.; Zhou, M.; Zhu, Z.; Lin, S.; Zhang, B. Heritable gene targeting in zebrafish using customized TALENs. Nat. Biotechnol. 2011, 29, 699. [CrossRef]

71. Juliano, B. Varietal impact on rice quality. Cereal Foods World 1998, 43, 207-222.

72. Zhang, H.; Zhang, J.; Wei, P.; Zhang, B.; Gou, F.; Feng, Z.; Mao, Y.; Yang, L.; Zhang, H.; Xu, N.; et al. The CRISPR/C as9 system produces specific and homozygous targeted gene editing in rice in one generation. Plant Biotechnol. J. 2014, 12, 797-807. [CrossRef] [PubMed]

73. Tian, Z.; Qian, Q.; Liu, Q.; Yan, M.; Liu, X.; Yan, C.; Liu, G.; Gao, Z.; Tang, S.; Zeng, D.; et al. Allelic diversities in rice starch biosynthesis lead to a diverse array of rice eating and cooking qualities. Proc. Natl. Acad. Sci. USA 2009, 106, 21760-21765. [CrossRef] [PubMed]

74. Xu, R.F.; Li, H.; Qin, R.Y.; Li, J.; Qiu, C.H.; Yang, Y.C.; Ma, H.; Li, L.; Wei, P.C.; Yang, J.B. Generation of inheritable and "transgene clean" targeted genome-modified rice in later generations using the CRISPR/Cas9 system. Sci. Rep. 2015, 5, 11491. [CrossRef] [PubMed]

75. Elkonin, L.A.; Tsvetova, M.I. Heritable effect of plant water availability conditions on restoration of male fertility in the "9E" CMS-inducing cytoplasm of sorghum. Front. Plant Sci. 2012, 3, 91. [CrossRef] [PubMed]

76. Wen, L.; Liu, G.; Li, S.Q.; Wan, C.X.; Tao, J.; Xu, K.Y.; Zhang, Z.J.; Zhu, Y.G. Proteomic analysis of anthers from Honglian cytoplasmic male sterility line rice and its corresponding maintainer and hybrid. Bot. Stud. 2007, 48, 293-309.

77. Qi, J.; Ma, H.; Xu, J.; Chen, M.; Zhou, D.; Wang, T.; Chen, S. Proteomic analysis of bud differentiation between cytoplasmic male-sterile line and maintainer in tobacco. Acta Agron. Sin. 2012, 38, 1232-1239. [CrossRef]

78. Sheoran, I.S.; Ross, A.R.; Olson, D.J.; Sawhney, V.K. Differential expression of proteins in the wild type and 7B-1 male-sterile mutant anthers of tomato (Solanum lycopersicum): A proteomic analysis. J. Proteomics 2009, 71, 624-636. [CrossRef]

79. Zheng, R.; Yue, S.; Xu, X.; Liu, J.; Xu, Q.; Wang, X.; Han, L.; Yu, D. Proteome analysis of the wild and YX-1 male sterile mutant anthers of wolfberry (Lycium barbarum L.). PLoS ONE 2012, 7, e41861. [CrossRef]

80. Ivanov, M.; Dymshits, G. Cytoplasmic male sterility and restoration of pollen fertility in higher plants. Russ. J. Genet. 2007, 43, 354-368. [CrossRef] 
81. Teixeira, R.T.; Knorpp, C.; Glimelius, K. Modified sucrose, starch, and ATP levels in two alloplasmic male-sterile lines of B. napus. J. Exp. Bot. 2005, 56, 1245-1253. [CrossRef]

82. Warmke, H.; Lee, S.L.J. Pollen abortion in T cytoplasmic male-sterile corn (Zea mays): A suggested mechanism. Science 1978, 200, 561-563. [CrossRef] [PubMed]

83. Bergman, P.; Edqvist, J.; Farbos, I.; Glimelius, K. Male-sterile tobacco displays abnormal mitochondrial atp1 transcript accumulation and reduced floral ATP/ADP ratio. Plant Mol. Biol. 2000, 42, 531-544. [CrossRef] [PubMed]

84. Hanson, M.R.; Bentolila, S. Interactions of mitochondrial and nuclear genes that affect male gametophyte development. Plant Cell. 2004, 16, S154-S169. [CrossRef] [PubMed]

85. De Paepe, R.; Forchioni, A.; Chetrit, P.; Vedel, F. Specific mitochondrial proteins in pollen: Presence of an additional ATP synthase beta subunit. Proc. Natl. Acad. Sci. USA 1993, 90, 5934-5938. [CrossRef]

86. Sassa, H.; Oguchi, S.; Inoue, T.; Hirano, H. Primary structural features of the $20 \mathrm{~S}$ proteasome subunits of rice (Oryza sativa). Gene 2000, 250, 61-66. [CrossRef]

87. Benedetti, M.; Verrascina, I.; Pontiggia, D.; Locci, F.; Mattei, B.; De Lorenzo, G.; Cervone, F. Four Arabidopsis berberine bridge enzyme-like proteins are specific oxidases that inactivate the elicitor-active oligogalacturonides. Plant J. 2018, 94, 260-273. [CrossRef] [PubMed]

88. Clark, G.B.; Morgan, R.O.; Fernandez, M.P.; Roux, S.J. Evolutionary adaptation of plant annexins has diversified their molecular structures, interactions and functional roles. New Phytol. 2012, 196, 695-712. [CrossRef]

89. Schnurr, J.; Shockey, J. The acyl-CoA synthetase encoded by LACS2 is essential for normal cuticle development in Arabidopsis. Plant Cell. 2004, 16, 629-642. [CrossRef]

90. Lallemand, B.; Erhardt, M.; Heitz, T.; Legrand, M. Sporopollenin biosynthetic enzymes interact and constitute a metabolon localized to the endoplasmic reticulum of tapetum cells. Plant Physiol. 2013, 162, 616-625. [CrossRef]

91. Shi, J.; Cui, M.; Yang, L.; Kim, Y.J.; Zhang, D. Genetic and biochemical mechanisms of pollen wall development. Trends Plant Sci. 2015, 20, 741-753. [CrossRef]

92. Kubo, A.; Fujita, N.; Harada, K.; Matsuda, T.; Satoh, H.; Nakamura, Y. The starch-debranching enzymes isoamylase and pullulanase are both involved in amylopectin biosynthesis in rice endosperm. Plant Physiol. 1999, 121, 399-410. [CrossRef] 